\begin{abstract}
Research has indicated that police may not receive enough training in interviewing cooperative witnesses, specifically in use of the Cognitive Interview (CI). Practically, for the CI to be effective in real-world investigations, police investigators must be trained by law enforcement trainers. We conducted a three-phase experiment to examine the feasibility of training experienced law enforcement trainers who would then train others to conduct the CI. We instructed FBI and local law enforcement trainers about the CI (Phase I); law enforcement trainers from both agencies $(n=4,100 \%$ male, mean age $=50$ years $)$ instructed university students $(n=25,59 \%$ female, mean age $=21$ years $)$ to conduct either the CI or a standard law enforcement interview (Phase II); the student interviewers then interviewed other student witnesses $(n=50,73 \%$ female, mean age $=22$ years $)$ who had watched a simulated crime (phase III). Compared to standard training, interviews conducted by those trained by CI-trained instructors contained more information and at a higher accuracy rate, and with fewer suggestive questions.
\end{abstract}

This is the author manuscript accepted for publication and has undergone full peer review but has not been through the copyediting, typesetting, pagination and proofreading process, which may lead to differences between this version and the Version of Record. Please cite this article as doi: $10.1002 /$ jip.1518 


\section{Train-the-trainer: Methodology to Learn the Cognitive Interview}

Gathering intelligence is the lifeblood of security operations. Of the various sources of intelligence information, cooperative human observers are often the most informative sources to tap. Developing effective methods of eliciting information from such human sources is therefore critical for security. Over the past 30 years, research has uncovered a number of problematic interviewing procedures that have been demonstrated to lead to less information and sometimes less accurate information gathered from witnesses (Fisher, Schreiber-Compo, Rivard, \& Hirn, 2014). To address these problems, researchers have applied established principles of cognition and communication to improve investigative interviewing practices. The Cognitive Interview (CI) is one such method, and has proven to be successful at increasing the amount of information gathered from cooperative human sources (Fisher \& Geiselman, 1992). Across over 100 laboratory and field experiments and using a variety of test conditions and subjects, the CI has typically elicited considerably more information, and at a comparable or higher level of accuracy, than conventional information-gathering interview protocols (see Memon, Meissner, \& Fraser, 2010 for a meta-analysis, and Fisher \& Geiselman, 2018 for a recent review of the research).

Law enforcement, however, has been slow to adopt empirically validated best practice procedures about interviewing cooperative witnesses. More than a decade after the release of the National Institute of Justice (NIJ) guidelines for best practices of witness interviewing (Technical Working Group for Eyewitness Evidence, 1999), Schreiber-Compo, Gregory, and Fisher (2010) assessed the interviewing performance of experienced law enforcement investigators in South Florida and found many undesirable techniques, often at odds with the established guidelines. Notably, law enforcement interviewing practices remained virtually unchanged from what was 
observed in an earlier Fisher, Geiselman, and Raymond (1987) study, in which investigators exhibited similarly poor interviewing techniques. Recently, Hirn-Mueller, Schreiber Compo, Molina, Bryon, and Pimentel (2015) examined law enforcement investigators' perceptions of scientifically validated interviewing techniques recommended in the NIJ guidelines. Although the investigators were aware of the efficacy of best practice techniques, only $14.6 \%$ of the investigators reported receiving training based on these techniques. Merely being aware of effective interviewing techniques is likely insufficient as the CI (and comparable procedures) requires substantial training to be implemented properly. A lack of investigator training could explain Schreiber-Compo et al.,'s (2010) observed discrepancy between interviewing practices and empirical recommendations. These findings underscore the need to develop effective interviewing training for law enforcement.

Police training academies in the United States may not prepare students adequately for interviewing cooperative witnesses (Reaves, 2009; Hickman, 2005; Bradford \& Pynes, 1999). Bradford and Pynes (1999) found in their review of 22 police academy curricula less than $3 \%$ of training time is devoted to "cognitive" aspects of law enforcement. A brief review of police academy curricula from New York, Florida, Kansas, and California reveal an average training time of 2 hours for interviewing cooperative witnesses. Although law enforcement may receive training later in their careers, advanced training for detectives only infrequently takes the form of additional formal instructional time. Instead, detectives acquire advanced interviewing skills "on the job" from other detectives in their unit (Alpert \& Dunham, 1997). Unfortunately, if best practice interviewing procedures are unknown or ineffectively implemented by senior detectives, then "on the job" training will fail to instruct new detectives on these procedures. 
Law enforcement while proficient in many forms of investigative interviewing, may benefit from evidence-based training in cooperative witness interviewing (specifically with the CI). Although many research psychologists have provided advanced empirically based interviewing training to the law enforcement community (e.g., Memon, Holley, Milne, Koehnken, \& Bull, 1994; Price \& Roberts, 2011; Lamb, Sternberg, Orbach, Hershkowitz, Horowitz \& Esplin, 2002), this approach remains ineffective for comprehensive national training. There are simply not enough academic experts in the CI to train the vast number of law enforcement agents who require CI training. Additionally, although an academic's CI training has been demonstrated effective for instructing college students to conduct CIs, it may not be well suited to training law enforcement officers. Memon and colleagues (1994) investigated the effects of training experienced law enforcement officers in the CI. The training program was unfortunately unsuccessful in passing on knowledge of the CI to police. Participants did not internalize the CI components and consequently did not generate more information from witnesses. The failure of the training to pass on CI techniques, given the success of CI training of law enforcement by academics using similar training content and length (e.g., Fisher, Geiselman, \& Amador, 1989), might be accounted for based on who the instructors were rather than insufficient instruction/training time. In their survey of police perceptions toward academics Telep and Lum (2014) showed that on the whole, personal operational experience was valued over empirical evidence, with many reporting that the work of scientists/academics was not particularly useful to their work. While the Telep and Lum survey was based on a fairly limited sample of American police departments it implies that for training law enforcement it may be critical to have the training conducted by other law enforcement trainers and not by academics. A viable and ecologically valid solution would be to employ a train-the-trainer 
methodology, in which law enforcement trainers are trained in the CI by a researcher and then communicate their CI training to the general law enforcement community (e.g., Lum, Koper, \& Telep, 2011; Alpert, Rojek, \& Hansen, 2013). The current study sought to take a first step in passing on the science of empirically based interviewing to law enforcement by determining if instructing experienced law enforcement trainers in the use and teaching of the CI would produce more effective interviewer trainees than those trained in standard police interviewing techniques.

Training in the CI condition was separated into three, 3-hour sessions. The content and length of current CI training sessions was based on methodology employed by Fisher and colleagues (1989), from the second author's prior experience training law enforcement with the CI, and taking into account the competing professional obligations facing our trainers who volunteered their time to participate in the current study. Whereas CI training was effectively standardized, a viable comparison group was needed to fairly represent typical law enforcement training. Two options emerged for the standard police training. The first option was to standardize elements of the standard training so that they matched the CI training (e.g., length, exercises, etc.). Doing so, however, would reduce the study's ecological validity, because we would be dictating to professional trainers how they must conduct "standard" police training (e.g., specified number of sessions and duration of each session), topics to cover, exercises to conduct, etc. The second option was to allow trainers the freedom to design training that would most closely resemble their actual interviewing training, given the specific parameters of the study (e.g., cooperative student witnesses observing videotaped crime). Allowing the standard trainers to design their own training regimen would increase the ecological validity, but at a cost to the internal validity of the experiment. Ultimately we decided to use the ecologically valid solution as it allowed us to demonstrate that CI training could be passed on to law enforcement 
interviewing trainers and that those trainers could produce superior interviewers in comparison to what is actually being done in the field by law enforcement trainers.

The goal of the present study was to therefore to compare the quality of witness interviews conducted by those trained by law enforcement trainers using standard police training procedures and by those trained by law enforcement trainers who were instructed to use the CI. The witness interviewing literature typically finds that witnesses administered a CI produce more information in interviews and that interviewers administering a CI are typically less likely to ask suggestive questions, based partially on increased use of open-ended questions (see Memon, Meissner, \& Fraser, 2010). Based on these findings, we predicted that interviewers instructed by CI-trained trainers would elicit more information from their witnesses than those trained in the standard fashion. We also predicted that CI-trained interviewers would engage in better interviewing behaviors, specifically, that CI-trained interviewers would ask (a) fewer questions, (b) more open-ended questions, and (c) fewer suggestive questions.

\section{Method}

\section{Participants}

Trainers. Four trainers were recruited through a local FBI Field office and a large local police department. Trainers were all male, with ages ranging from $44-58$ years-old $(M=50$ years-old, $S D=6.13$ ) All of the trainers were experienced law enforcement agents/detectives (mean years in law enforcement $=22$ years) as well as experienced as trainers for law enforcement (mean years as trainers $=14$ years), each certified in forensic interview training. All trainers had been conducting interviewing training in their respective agencies for a minimum of 10 years and were certified by their agency to conduct interviewing training. One trainer from local law 
enforcement and one trainer from the FBI were assigned randomly to the CI training condition. The remaining local law enforcement and FBI trainers were assigned to a standard interviewing (SI) condition and received no CI training.

Interviewers. Twenty-five interviewers were recruited primarily through an email sent out to undergraduate students through academic advising at a large public university. To ensure that the student interviewers would be serious and motivated, we contacted only Psychology majors with a GPA of 3.0 or higher. Students were assigned randomly to either a CI or standard training condition taking into account student availability. Fifty-nine percent of the student interviewers were female, with ages ranging from $19-26$ years-old $(M=21$ years-old, $S D=2.15)$. Interviewer ethnicity corresponded to the demographics of the university with $55 \%$ of the interviewers identifying as Hispanic (Latina/o), 27\% identifying as African American, 14\% identifying as Caucasian (not Hispanic) and 5\% identifying as another ethnicity.

Witnesses. Witness participants were undergraduate students recruited primarily through the University Psychology student subject pool $(\mathrm{n}=50)$. Participants were primarily female $(73 \%)$ with ages ranging from $18-47$ years-old $(M=22$ years-old, $S D=3.62)$. Participants received either $\$ 10$ or research credit toward their psychology classes. Similar to our interviewers, ethnic identification corresponded to the demographics of the university population with $50 \%$ of witnesses identifying as Hispanic, Latina/o), 32\% identifying as African American, 14\% identifying as Caucasian (not Hispanic), and 5\% identifying as another ethnicity.

Interview environment and recording. All interviews took place in small, plain rooms containing two chairs and a desk or table. The interviewer and witness were seated directly across from one another. Interviews were recorded on digital audio recorders. 
Crime videos. Two videos were used as stimulus materials. Both were excerpts taken from older Hollywood movies, and were selected based on their richness in detail and date of release (both movies were released at least two decades previously, ensuring that few participants had seen them prior to the study). One video excerpt involved two armed robbers assaulting a coffee shop and stealing from the customers. The other video excerpt involved an armed bank robbery involving three suspects. Each clip was approximately five minutes in length. All participants watched the film on a 32-inch television and were seated approximately five feet from the screen.

\section{Procedure}

Phase 1: Training the trainer. The FBI and local law enforcement trainers selected for the CI condition met for 4 training sessions lasting approximately 3-4 hours each. Both trainers attended CI training sessions together and both reported little to no exposure to the CI prior to training.

The first training session focused on the theoretical background and social dynamics of the CI, including: rapport building, establishing the roles of the witness (actively generates information) and interviewer (refrains from asking many questions), allowing sufficiently for pauses in reporting, and finally that the witness should report everything but should not guess. The second day of training centered on the cognitive and memory-based CI components and included the principles of context reinstatement and the benefits of eye closure. On the third day of training communicative elements of the CI were discussed (e.g., not interrupting the witness, use of a sketch, etc.). The fourth session centered on how to effectively train individuals in the CI. Additionally, a variety of role-playing exercises were explained, each of which centered on a different CI element. Several exercises were intended to be in-class exercises (for which trainers 
were made aware of common mistakes and were taught ways of providing effective criticism to interviewers), and others to be homework. Role-playing exercises involved small practice groups in which student trainees either played a witness or an interviewer (students rotated roles throughout the course of training sessions). The trainers monitored these small group exercises and provided feedback at the conclusion of each practice session. Homework involved students conducting interviews with friends or relatives outside of the training session times and returning with an audio recording which was critiqued by the trainer and discussed with the group. Training videos used during this training session included examples of good and poor interviewing techniques.

Trainers selected for the standard interview conditions met individually for one session with the research team. These sessions involved answering questions about the study, the attributes of the students they would be instructing, as well as acclimatizing trainers to the training rooms and equipment available (e.g., whiteboard, video and audio playback). Standard interview trainers were instructed to develop lesson plans that were representative of their typical training for cooperative witness interviewing. The local law enforcement standard trainer requested a single training session of two hours, and the FBI standard trainer requested two, 2hour training sessions. Standard trainers were informed during this meeting that the focus of the experiment was on cooperative witnesses and therefore they should operate under the assumption that no deception detection or interrogative training would be needed.

Phase 2: Training the interviewer. Participants assigned to the interviewer role arrived in groups of approximately six students. All training sessions began with a brief introduction as to the purpose of the study and the participants' role in the research as forensic interviewers. 
The topics covered in the CI training of student interviewers followed the same sequence as the training of law enforcement trainers, namely, Day 1: Social Dynamics; Day 2: Cognition; Day 3: Communication. Throughout the CI training students engaged in role-playing exercises to practice interviewing techniques. Additionally, students were assigned homework activities between sessions involving interviewing a friend or family member using the CI. (We monitored, via closed-circuit television, the trainers conducting the training sessions: The CI trainers covered all of the essential elements of the CI that they were instructed to cover in Phase I.) Upon conclusion of training the interviewers were given an outline of all the elements of the CI and were told to review the outline before coming to their scheduled interviews.

Standard Interview Training. Each standard trainer was allowed to develop his own training based on his conventional instruction methods. As such, the Local Law Enforcement and FBI standard trainings differed. The Local Law Enforcement standard interview training consisted of a single 2-hour training session. The training was largely discussion based and focused on three primary areas: (a) factors that may influence an interview (e.g. interview location, time of day, delay between the event and the interview, and victim/witness's relationship to offenders), (b) deception detection in victims and witnesses (e.g. body language, fact consistency, and contradictory physical evidence), and (c) interview-relevant demographic factors (e.g. age, ethnicity, type of crime, and interviewer gender/ethnicity). The FBI standard training occurred over two days in 2-hour sessions. The first day of training centered on generally good interviewing techniques, including: building rapport, use of sketches, effective questioning, avoiding interruptions, active listening, and multiple retellings of the event in question. The second day involved an exercise on active listening and applying the techniques learned on the previous day of training. 
Phase 3: Conducting the interviews. The student interviewer and witness arrived separately for each interview session. Interviewers were first instructed that they would be interviewing students who watched a video of a mock crime. The interviewers then waited alone in the interview room to prepare for the interview. Witnesses viewed one of the two simulated crime videos in the viewing room. After viewing the videos, witnesses were escorted to a separate room with an interviewer to conduct the witness interview. All interview times were capped at 50 minutes, however no interviews went over 50 minutes (mean time $=22.53$ minutes). Interviewers each completed a total of two witness interviews (one for each of the crime videos); the order was counterbalanced across interviewers and experimental conditions.

\section{Results}

We present the data only in terms of the effects of training (CI or standard). We do not describe the differences between the FBI trainers and the local police department trainers because there was only one person who served as the trainer for each combination of training (CI or standard) and agency (FBI or local police). Thus, any differences between the FBI and the local police department are likely to reflect the specific individuals who served as the trainer.

\section{Inter-rater Reliability}

Fifteen percent $(n=8)$ of the transcripts were co-scored to establish inter-rater reliability for adherence to the CI. For (a) question type, (b) parsing into meaningful units of information, and (c) accuracy $20 \%(n=10)$ of transcripts were double coded to check for interrater reliability. For the purposes of coding, open-ended questions were questions thought to elicit extensive information (e.g., "What happened?", "Describe the suspect," etc.), while close-ended questions were questions viewed as more targeted in their informative focus (e.g., "What color with the get-away car?", "How old was the suspect," etc.). Measures of units of information were 
obtained by breaking down statements into component parts. For example "The man with the blue shirt had a gun," would count as four units of information: "man", "blue", "shirt", and "gun". Units of information that were repeated were also coded and parsed separately from new units of information gained e.g., "The man ran into the kitchen," - "man" would be coded as a repeated unit of information since it had been coded in the previous statement. Intra-class correlations, recommended for assessing inter-rater reliability for continuous variables, were used (e.g., Prieto, Lamarca, Casado, \& Alonso, 1997). Inter-rater correlations were .99 for parsing into meaningful units, .91 for accuracy, .71 to .99 for question type (open-ended, confirmatory, yes/no, cued-recall, and option posing), and .77 for overall adherence to the CI.

\section{Interviewers' Questioning Behaviors}

Adherence. CI-trained interviewers were coded for adherence to the CI to serve as a manipulation check that CI trained interviewers were actually conducting CIs and was not, as such, a primary dependent measure. Adherence was coded in terms of whether the interviewer made an attempt at any time during the interview to implement a specific element of the interview. Generally, the interviewers adhered to the CI protocol (see Table 1): Of the eleven elements of the CI, 7 were implemented by virtually all of the CI-trained interviewers (96\% 100\%): rapport, open-ended questions, no interruptions, draw sketch, detailed description, multiple retrieval, and close eyes. Of the remaining 4 elements, all were implemented by at least $67 \%$ of the interviewers: don't guess; show ideal interview; explicit statement of social dynamics, and context reinstatement.

--Insert Table 1 about here-- 
Number of Questions Asked._As expected, the CI-trained interviewers asked fewer questions $(M=19.91,[11.97-27.85])$ than the standard-trained interviewers $(M=65.91,[43.19$ $-88.64]), t(45)=4.17, p<.001,(d=1.24)$.

Proportion of Open-ended Questions Asked. Again, as expected, of all the questions asked, CI-trained interviewers asked proportionally more open-ended questions, $(M=.37,[.31$ $.44])$ than did the standard-trained interviewers $(M=.13,[.10-.16]), t(45)=6.15, p<.001,(d=$ $1.83)$.

Breakdown of Proportions of Closed Questions Asked. Within all closed-questions (including confirmatory, yes/no, cued recall, option posing, and questions), significant differences were found for the proportion of confirmatory questions asked: CI-trained interviewers asked significantly fewer confirmatory questions (questions that are intended to verify generated information, e.g., "So you said that there were two suspects in the diner?") (M $=.18,[.09-.26])$ compared to standard-trained interviewers $(M=.43,[.36-.50]), t(45)=7.23, p$ $<.001,(d=2.16)$. CI-trained interviewers asked marginally fewer yes/no questions $(M=.30$, $[.24-.36])$ compared to standard-trained interviewers $(M=.41,[.30-.53]), t(45)=1.81, p=.07$, $(d=.54)$. CI-trained interviewers asked proportionately more cued-recall questions (e.g., "What color was the suspect's car?") $(M=.35,[.25-.45])$ compared to standard-trained interviewers $(M$ $=.21,[.17-.25]), t(45)=2.77, p=.008,(d=.83)$ (note that for raw numbers of questions CItrained interviewers asked far fewer cued-recall questions $(M=3.42)$ compared to standardtrained interviewers $(M=13.35)$. No differences were observed for option-posing questions (questions where the interviewer proposes a limited set of alternatives for the interviewee to chose from) across CI and standard-trained interviewers $(p=.81)$. 
Suggestive Questions Asked. Finally, as expected, CI-trained interviewers asked proportionately fewer suggestive questions $(M=.11)$ than standard-trained interviewers $(M=.23)$, $t(45)=3.44, p<.001,(d=1.03)$.

Interview Time. Interviewers in the CI condition took significantly longer to conduct their interviewers $(M=26.38$ minutes, [22.43 - 30.34]) compared to interviews conducted by standard-trained interviewers $(M=18.52$ minutes, $[13.56-23.48]), t(45)=2.49, p=.01,(d=$ $.74)$.

\section{Information Gathered from Witnesses}

Amount of information generated. We counted the number of unique units of information per witness; thus, if a witness repeated a statement during the interview, we counted this as only one piece of information. The CI-trained interviewers elicited almost $50 \%$ more information $(M=121.19)$ than did standard-trained interviewers $(M=83.00,[103.49-138.89])$, $t(46)=3.17, p=.003(d=.93)$.

Accuracy of information generated. Accuracy rate was an output-bound measure (Koriat \& Goldsmith, 1994). For each witness, we assessed the accuracy of each item reported by (a) comparing it to what actually happened, as portrayed in the witnessed video), and then (b) calculating the proportion of all items reported that were correct, i.e. $\frac{(\# \text { Correct })}{[(\# \text { Correct })+(\# \text { Incorrect })]}$. We did not differentiate between complete fabrications (reporting something that was not available in the video, e.g. indicating that the robber had a tattoo on his arm, if he was wearing a jacket that covered his arm) and mistaken reports (reporting something inaccurately that was in the video e.g. saying that the robber wore a blue jacket when, in fact, the jacket was red.) The information gathered by CI-trained interviewers was significantly more accurate $(M=.97$, [.96 - 
$.98])$ than that gathered by standard-trained interviewers $(M=.95,[.94-.96]), t(45)=2.07, p=$ $.04,(d=.61)$.

\section{Discussion}

The current study demonstrated that experienced law enforcement trainers can be trained to instruct others to conduct the CI effectively. Students instructed by CI-trained trainers generally adhered to the elements of the CI. Interviewers trained in the CI (a) asked relatively few questions (encouraging the witness to do most of the talking), (b) asked a high proportion of open-ended questions (again, encouraging witnesses to do most of the talking), and (c) asked relatively few suggestive questions (thereby promoting high accuracy). Most important, CItrained interviewers elicited more information from witnesses, and at a higher accuracy rate, than interviewers given conventional training.

Our finding that CI training yielded more information than the standard training reflects earlier work (see Memon et al., 2010). However, the actual size of the observed CI advantage (nearly $50 \%$ or 41.5 units of additional information) was substantially higher than is typically found in laboratory studies. Interestingly this finding mirrors the 50\% - 60\% increase found in the Fisher, Geilselman, and Amador (1989) field study with actual victims and witnesses of crime (see also Colomb, et al., 2013, for similar field study findings). Our finding that the CIelicited information was significantly more accurate (.97 accuracy rate) than the standard-elicited information (.95), is not typically found in the literature. While improved CI accuracy is a potentially noteworthy finding, the relatively small accuracy rate difference and our limited internal validity may mitigate its importance. Critically, our CI accuracy was not lower than the standard interview. Finding equivalent rates with the $\mathrm{CI}$ is critical for appreciating its utility, as 
otherwise one might argue that the increased amount of information gathered by the CI is merely a quantity-accuracy tradeoff (see, Koriat \& Goldsmith, 1996).

The quantity and accuracy of information gathered provides compelling evidence that the CI was successfully passed on from trainer to interviewers. As a secondary issue we also sought to understand the behavioral differences across CI and standard interviewers. Very little research has explored how CI-trained interviewers actually conduct interviews. The present study showed that, compared to their standard-trained counterparts, the CI-trained interviewers asked relatively few questions, and these were mostly open-ended and non-suggestive. If interviewers ask relatively few questions (as in the present CI-trained interviews), the interviewer is unlikely to influence the witness's response. Interviewers who play a more active, and perhaps controlling, role in the interview may increase witness inaccuracies/confabulation (as observed in the standard-trained interviews). In a related fashion, our CI-trained interviewers tended to ask open-ended questions thereby allowing the retrieval process to be driven mainly by the witness. By comparison, our SI-trained interviewers asked more specific, closed questions (e.g. "What color was the robber's hair?"), such that the targeted information was directed by the questionasker. Finally, because our CI interviewers asked virtually no suggestive questions, they should be perceived as not attempting to influence the witness. We would expect, therefore, that if people listened to our interviews, they would assess the witness's statement as being relatively uninfluenced by the interviewer and, as such, a true product of his/her memory (see Fisher, Mello, \& McCauley, 1999 and Mello, McCauley \& Fisher, 1995).

What aspect of the CI training promoted these outcomes? We can only speculate, as the CI training differed from the standard training in many respects. Compared to the standard training, the CI training (a) included more specific elements of the CI protocol and explained 
more thoroughly why each element was included (b) was more extensive (three 3-hour sessions versus either one or two 2-hour sessions), (c) included role-playing exercises with feedback, and (d) provided "homework" assignments and subsequent discussion. We suspect that each of these training elements contributed to the overall effectiveness of the CI training but we cannot be certain how much each independent element may have contributed to the CI's effectiveness. We note that the standard trainers also included instructions to ask open-ended questions and to avoid asking suggestive questions (and the FBI Standard trainer also informed the trainees to ask witnesses to draw a sketch); nevertheless, their trainees were less likely to incorporate these elements into their actual interviews. Why were many of the standard trainers' instructions not integrated into their trainees' interviews? One possible explanation might be the contradictory nature of standard training content. While trainers acknowledged the importance of open-ended questions the vast majority of examples, demonstrations and trainee practice predominantly included close-ended questions and completing mental "check-lists" of information trainers viewed as having investigative importance. Similarly, standard trainers raised topics such as rapport building, but failed to provide concrete steps that interviewer trainees could actually develop rapport. Clearly, training needs to provide more than just basic instructions on how to conduct interviews. Such instructions, we suspect, need to be supplemented with explanations about why and how the suggested elements work, and exercises that provide opportunity for the trainees to practice the recommended procedures. Consequently, a fruitful area of follow-up research is to isolate each of these aspects of training to assess the relative impact of each element (although see Fisher, 2010 for the difficulty in isolating individual CI elements).

One important limitation of the current research is that the trainees/interviewers were students who had no prior formal training or experience conducting witness interviews. For CI 
training to be effective in a real-world setting, research must be conducted on training law enforcement and intelligence-gathering professionals. Although, on the surface, this may seem easier than training inexperienced students, we suspect that it may prove to be more difficult, as many law enforcement agents may have developed other interviewing habits over the years that may require unlearning in order for CI training to be effective (see, e.g. Fisher et al., 1987; Fisher, \& Schreiber, 2007). As first identified by Memon and colleagues (1994) training police officers in the CI is not an easy undertaking as old interviewing habits may inhibit the application of newer tactics. The United Kingdom has developed a potential solution to this with the introduction of gradual interviewing training via the PEACE training model and Professionalizing Interview Programme (PIP) (National Investigative Interviewing Strategy, 2009). PIP seeks to gradually train investigators with increasing depth of training as they progress in their careers and concurrently develop an increased need for advanced interviewing training. While these initiatives are an important step forward, positive changes in interviewing practices by police using this system may be slower to develop (see Clark \& Milne, 2001; Walsh \& Milne, 2008; Clark, Milne, \& Bull, 2011). Importantly, further research into training actual law enforcement professionals at various levels, both inside and outside the laboratory is needed to fully understand the challenges of training law enforcement in best practice interviewing procedures.

Any effective training program, whether interviewing witnesses or any other procedural skill, will need to deal with the following issues. As such, we should look to the general training literature for guidance. 1. How flexible should the training program be? Should a standardized training manual be followed closely by all trainers, or should trainers be given extensive flexibility to introduce their own approach? 
2. How and when should training on interviewing cooperative witnesses be introduced in investigators' careers? Given that investigators are likely to be assigned to simple cases initially in their investigative careers (which will benefit less from the CI than will complex cases), should the CI be introduced only later in investigators' careers? But, late-career training creates the opportunity for investigators to develop poor interviewing practices—or at least poor for complex cases that benefit from a CI approach.

3. How well does CI training hold up over time, or will trainees revert to their pre-training tactics over time? If so, then an integral part of training will entail providing refresher training or something comparable to solidify the benefits of CI training.

4. As Meissner, Redlich, Bhatt, and Brandon (2012) have discussed, use of the CI to interview suspects with a focus on intelligence gathering (rather than obtaining a confession) is a burgeoning area of research. How might training in a suspect focused CI differ from a witness centered CI? Would new training procedures need to be implemented in order to effectively capture the CI's effectiveness in suspect interviews?

The training issues listed are not unique to CI training. Rather, these are issues shared across many areas of law enforcement training, which might be informative in improving the quality of future CI training.

Training is an integral part of ensuring effective law enforcement and homeland security practice. Although training to interview cooperative witnesses is often overlooked (Bradford \& Pynes, 1999), the need for productive interviewers is critical to the needs of our society. Our experiment demonstrates that training experienced trainers can indeed lead to more effective interviews and underscores the importance of passing on the science of memory improvement to law enforcement and intelligence operations. The current study is an important first step in 
passing on the products of empirical research to where it is critically needed operationally. In some circumstances current training practices may be preferable given the needs and resources of a particular law enforcement organization. Ultimately law enforcement administration should decide how best to implement these findings within the constraints of current training programs and their unique investigative needs. We challenge psychologists to continue research in this vein and better communicate a scientific approach to investigative practice. 


\section{References}

Alpert, G. P., \& Dunham, R. G. (1997). Policing Urban America. Prospect Heights, IL: Waveland Press.

Alpert, G. P., Rojek, J., \& Hansen, A. (2013). Building Bridges Between Police Researchers and Practitioners: Agents of Change in a Complex World. Washington, DC: National Institute of Justice.

Bradford, D., \& Pynes, J. (1999). Police Academy Training: Why Hasn’t It Kept Up With Practice? Police Quarterly, 2, 283-301. doi: http://dx.doi.org/10.1177/109861119900200302

Clarke, C., \& Milne, R. (2001). National evaluation of the PEACE investigative interviewing course. Police Research Award Scheme. London, UK: Home Office

Clarke, C., Milne, R., \& Bull, R. (2011). Interviewing suspects of crime: The impact of PEACE training, supervision and the presence of a legal advisor. Journal of Investigative Psychology and Offender Profiling, 8, 149-162. doi:10.1002/jip.144

Colomb, C., Ginet, M., Wright, D., Demarchi, S., \& Sadler, C., (2013). Back to the real: efficacy and perception of a modified cognitive interview in the field. Applied Cognitive Psychology, 27 doi: http://dx.doi.org/10.1002/acp.2942

Fisher, R. P. (2010). Interviewing cooperative witnesses. Legal and Criminological Psychology, 15, 25-38. doi: http://dx.doi.org/10.1348/135532509X441891

Fisher, R., \& Geiselman, R. (1992). Memory-enhancing techniques for investigative interviewing. Springfield, IL., Charles C Thomas Publishers.

Fisher, R., Geiselman, R., \& Amador, M. (1989). Field test of the cognitive interview: 
Enhancing the recollection of the actual victims and witnesses of crime. Journal of Applied Psychology, 74, 722-727. http://dx.doi.org/10.1037//0021-9010.74.5.722

Fisher, R. P., Geiselman, R. E., \& Raymond, D. S. (1987). Critical analysis of police interview techniques. Journal of Police Science and Administration, 15, 177-185.

Fisher, R., Mello, E., \& McCauley, M. (1999). Are jurors' perceptions of eyewitness credibility affected by the cognitive interview?. Psychology, Crime \& Law, 5, 167-176. doi: http://dx.doi.org/10.1080/10683169908414999

Fisher, R. P., Schreiber Compo, N., Rivard, J. R., \& Hirn, D. (2014). Interviewing witnesses. In T. Perfect, \& D. S. Lindsay (Eds.), The SAGE handbook of applied memory. Stamford, CT: Cenveo Inc. doi: http://dx.doi.org/10.1002/acp.3026

Hickman, M. J. (2005). State and Local Law Enforcement Training Academies, 2002, Bureau of Justice Statistics, Washington, DC.

Hirn Mueller, D., Schreiber Compo, N., Molina, J., Bryon, A., \& Pimentel, P. (2015). Productive and counterproductive interviewing techniques: Do law enforcement investigators know the difference?. Psychology, Public Policy, And Law, 21, 295-308.

doi: http://dx.doi.org/10.1037/law0000047

Koriat, A., \& Goldsmith, M. (1996). Monitoring and control processes in the strategic regulation of memory accuracy. Psychological Review, 103, 490-517. doi: http://dx.doi.org/10.1037//0033-295x.103.3.490

Lamb, M. E., Sternberg, K. J., Orbach, Y., Hershkowitz, I., Horowitz, D., \& Esplin, P. W. (2002). The effects of intensive training and ongoing supervision on the quality of investigative interviews with alleged sex abuse victims. Applied Developmental Science, $6,114-125$.

This article is protected by copyright. All rights reserved. 
Lum, C., Koper, C. S., \& Telep, C. W. (2011). The evidence-based policing matrix. Journal of Experimental Criminology, 7, 3-26. doi: $\underline{\text { http://dx.doi.org/10.1007/s11292-010-9108-2 }}$

Meissner, C., Redlich, A., Bhatt, S., \& Brandon, S. (2012). Interview and interrogation methods and their effects on investigative outcomes. Campbell Systematic Reviews, doi: http://dx.doi.org/10.4073/csr.2012.13

Memon, A., Holley, A., Milne, R., Koehnken, G., \& Bull, R. (1994). Towards understanding the effects of interviewer training in evaluating the cognitive interview. Applied Cognitive Psychology, 8, 641-659.

Memon, A., Meissner, C., \& Fraser, J. (2010). The Cognitive Interview: A meta-analytic review and study space analysis of the past 25 years. Psychology, Public Policy, And Law, 16, 340-372.doi: http://dx.doi.org/10.1037/a0020518

Mosser, A., Fisher, R., Molinaro, P., Satin, G., \& Manon, M. (2016, March). Train-the-trainer: Training law enforcement investigators in the CI. Paper presented at American Psychology-Law Society. Atlanta, GA. Abstract retrieved from http://ap1s.wildapricot.org/resources/Documents/AP-LS2016/2016ConferenceProgram.pdf

National Investigative Interviewing Strategy (2009). Retrieved 13 October, 2017 from: http://library.college.police.uk/docs/npia/BP-Nat-Investigative-Interviewing-Strategy2009.pdf

Price, H. L., \& Roberts, K. P. (2011). The effects of an intensive training and feedback program on police and social workers' investigative interviews of children. Canadian Journal of Behavioural Science, 43, 235.

Prieto, L., Lamarca, R., Casado, A., \& Alonso, J. (1997). The evaluation of agreement on 
continuous variables by the intraclass correlation coefficient. Journal of Epidemiology and Community Health, 51, 579-581. doi: http://dx.doi.org/10.1136/jech.51.5.579-a

Reaves, B. A. (2009). State and Local Law Enforcement Training Academies, 2006. Washington, DC: Bureau of Justice Statistics.

Schreiber Compo, N., Hyman Gregory, A., \& Fisher, R. (2012). Interviewing behaviors in police investigators: a field study of a current US sample. Psychology, Crime \& Law, 18, 359375. doi: http://dx.doi.org/10.1080/1068316x.2010.494604

Telep, C. W., \& Lum, C. (2014). The receptivity of officers to empirical research and evidencebased policing: An examination of survey data from three agencies. Police Quarterly, 17(4), 359-385. doi:10.1177/1098611114548099

U.S. Department of Justice. (1999). Eyewitness evidence: A guide for law enforcement. Washington, DC: Office of Justice Programs.

Walsh, D. W., \& Milne, R. (2008). Keeping the PEACE? A study of investigative interviewing practices in the public sector. Legal and Criminological Psychology, 13, 39-57. doi:10.1348/135532506X157179

This article is protected by copyright. All rights reserved. 
Table 1

CI Adherence in CI Condition Witness Interviews by Technique

\begin{tabular}{rcc} 
CI Technique & Frequency & Percentage \\
\cline { 2 - 3 } Rapport Building & 24 & $100.0 \%$ \\
Ideal Interview & 19 & $79.2 \%$ \\
Dynamics & 17 & $70.8 \%$ \\
Explicit Statement of Social & 24 & $100.0 \%$ \\
Open-ended Questions & 24 & $100.0 \%$ \\
Context Reinstatement & 18 & $75.0 \%$ \\
Close-eyes Instruction & 23 & $95.8 \%$ \\
No Guessing Instruction & 16 & $66.6 \%$ \\
Detailed Description & 24 & $100.0 \%$ \\
Instruction & 23 & $95.8 \%$ \\
Draw Sketch & 24 & $100.0 \%$ \\
\hline Multiple Retrieval Attempts & &
\end{tabular}

This article is protected by copyright. All rights reserved. 